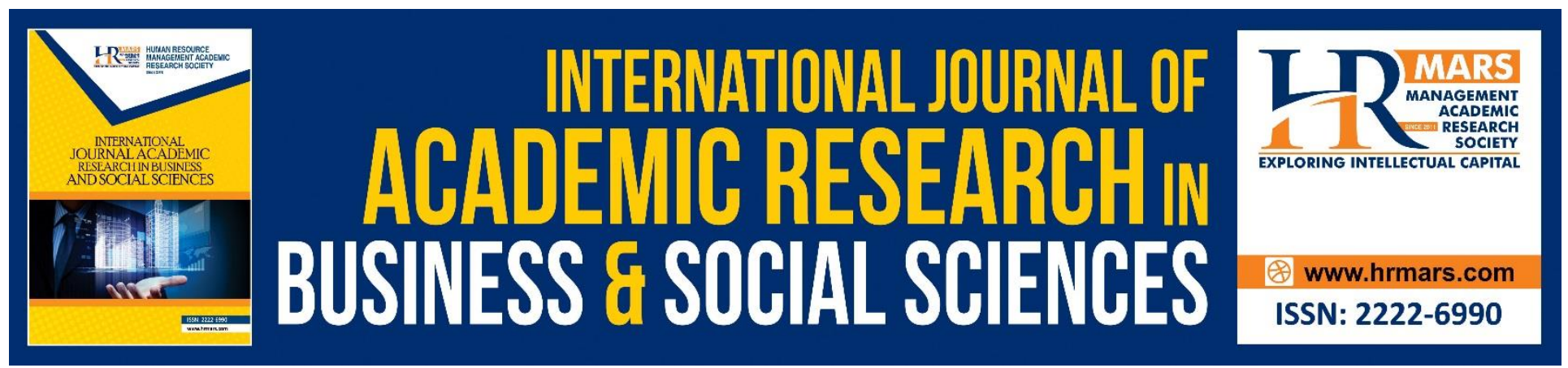

\title{
The Role of Family Constraints and their Relation in Preparation and Rehabilitation Child Autistic in the Governorate of Irbid in Jordan
}

Thawab al-Quran, Nashaat Baioumy \& Ab Aziz Sulaiman

To Link this Article: http://dx.doi.org/10.6007/IJARBSS/v8-i11/4909

DOI: 10.6007/IJARBSS/v8-i11/4909

Received: 08 Oct 2018, Revised: 24 Oct 2018, Accepted: 16 Nov 2018

Published Online: 28 Nov 2018

In-Text Citation: (Al-Quran, Baioumy, \& Sulaiman, 2018)

To Cite this Article: Al-Quran, T., Baioumy, N., \& Sulaiman, A. A. (2018). The Role of Family Constraints and their Relation in Preparation and Rehabilitation Child Autistic in the Governorate of Irbid in Jordan. International Journal of Academic Research in Business and Social Sciences, 8(11), 364-373.

Copyright: (c) 2018 The Author(s)

Published by Human Resource Management Academic Research Society (www.hrmars.com)

This article is published under the Creative Commons Attribution (CC BY 4.0) license. Anyone may reproduce, distribute, translate and create derivative works of this article (for both commercial and non-commercial purposes), subject to full attribution to the original publication and authors. The full terms of this license may be seen

at: http://creativecommons.org/licences/by/4.0/legalcode

Vol. 8, No. 11, 2018, Pg. 364 - 373

http://hrmars.com/index.php/pages/detail/IJARBSS

JOURNAL HOMEPAGE

Full Terms \& Conditions of access and use can be found at http://hrmars.com/index.php/pages/detail/publication-ethics 


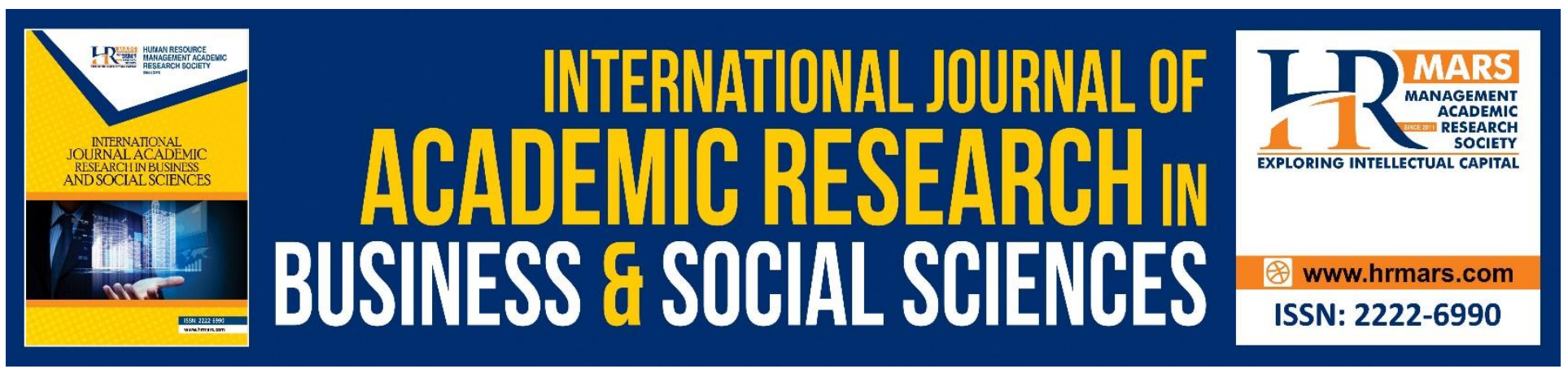

\title{
The Role of Family Constraints and their Relation in Preparation and Rehabilitation Child Autistic in the Governorate of Irbid in Jordan
}

\author{
Thawab al-Quran, Nashaat Baioumy \& Ab Aziz Sulaiman \\ Faculty of Islamic Contemporary Studies University of Sultan Zainal Abidin, 21300, Terengganu, \\ Malaysia
}

\begin{abstract}
Families in Jordan who have autistic children suffer greatly from many psychological, social and economic problems. There is no doubt that these problems result in constraints that affect the families' ability to play their roles towards the care of the autistic children. The present study aims to identify the nature of these family constraints, therefore, the researcher used the descriptive approach to analyze the literature and studies related to the study problem, to prepare the theoretical framework, to construct the study tool and to apply it and to analyze and interpret the results. A questionnaire was developed consisting of (28) paragraphs divided into four areas, the study sample consisted of (197) families with autistic children. The results of the study showed that the impact level of the psychological and economic constraints were very high, medium degree of social constraints and autistic child rehabilitation is largely performed by families. The results showed a difference in the level of psychological constraints according to the variables (family income as a whole, place of residence and type of family housing), while there is no difference according to the variables (father's educational level, mother's educational level and social status), and that there is a difference in the level of social constraints depending on the variables (educational level of the mother and the social situation) while there is no difference depending on the variables (father's educational level, family income and place of residence, there is a difference in economic constraints level according to the variables (father's educational level, mothers' educational level, family income, social status and type of residence). The study recommended the necessity of conducting training sessions with parents to discuss their needs and solve their problems related to their autistic child, activate the role of psychologist and social worker to help and provide appropriate solutions and to develop national programs to help families of children with autism financially.
\end{abstract}

Keywords: Autistic Child, Family constraints, Family Role, Irbid Governorate, Jordan. 


\section{Introduction}

The family is one of the most prominent social institutions established by man for his life and his continuity. The family must be characterized by normal relations within the family which based on love and respect that leads the child to a sense of security, self-esteem, and belief in his abilities and his desire to identify all new things around him.

There is no doubt that family problems and needs increase the sense of pressure which is reflected in the family consensus and stability therefore families cannot meet the needs of continuous change in the their cycle, and when the pressures increase accompanied with the increasing of external and psychological pressure, family issues cannot be solved, many Families at a certain point do not skip these problems (Refaat, 2006).

These problems increase when compound with the presence of an autistic child within the family. Autism is one of the developmental disabilities for children. It is the most difficult disabilities for the child and his family. Autism Symptoms are manifested during the first three years of the child's life, and impedes communication, learning and social interaction and it is characterized by social, cognitive and verbal development of the child. (Najjar, 2006).

\section{Study Problem}

The autistic child's family faces many constraints and difficulties that limit its ability to rehabilitate its autistic child, which leads the family to feel unstable and disrupts the psychological, social and physical organization of its members.

It is noticeable that families with low socio-economic status are often faced with the difficulty of providing their child support and consent which they need because of their total preoccupation with their daily needs; therefore, this preoccupation with securing a living does not allow parents to participate in activities to help the child; as a result of that separation between parents usually occurs (Imam \& Jawalda, 2010).

Previous studies indicated that there are many constraints facing the autistic child's family. The study of Ahmed Al-Za'arir (2009) showed that the Problems Occurs because of the fear of the child's future and needs. The results of (Holroyd et al, 1975) and (WolfLucille, 1989) indicated of difficulties associated with the autistic child treatment costs, in addition to the problems related to relations within the family and outside it, as proved by the study (Al-Khamees, 2011).

\section{Study Objectives}

In this study, the researcher tried to find out the impact of the psychological, social and economic constraints that limit the family role in the preparation and rehabilitation of autistic children in Irbid governorate in Jordan. As well as to know the family's role level in the preparation and rehabilitation of autistic child in the province of Irbid in Jordan.

\section{The Importance of the Study}

This study was designed to benefit from its results in designing and construction of educational and social programs prepared by social workers to alleviate the impact of constraints on families of autistic children, in addition to that the preparation of a proposed scenario that enables the families of autistic children to deal with the constraints that affect them in a studied educational methods, 
INTERNATIONAL JOURNAL OF ACADEMIC RESEARCH IN BUSINESS AND SOCIAL SCIENCES

Vol. 8, No. 11, Nov, 2018, E-ISSN: 2222-6990 (C) 2018 HRMARS

and to limit the family's role and exploits its efforts in preparing and qualifying the autistic child, especially in the Jordanian society.

\section{Study approach}

The descriptive approach was used to obtain information related to the current state of the phenomenon in order to determine its nature and to identify the interrelationships in their occurrence, description, imaging and analysis of the variables affecting their creation and growth.

\section{Study Society}

The society of the study is composed of families of autistic children who visit care and rehabilitation centers in the northern part of the Kingdom of Jordan in Irbid governorate to benefit from its services in alleviating the constraints facing families in the rehabilitation of autistic children. There are 15 Specialized Center for Special Education, Al-Baqa'i Center for Care and Rehabilitation, Jordan Aid Center for Special Education, Al awj for autistic children, Wasan Speclized center for autistic and special education, Maharat center for special education, Al Beqaei center for Care and Rehabilitation Jordan Aid Center for Special Education, Al-Shamal Academy for Training and Rehabilitation, West Irbid Center for Special Needs, Disabled Child Welfare Association, North gate for Association, SI Sabah Center, Ikleel AI Ward, Al Banfsaj for special Education, Community Rehabilitation Center, Reda Al Walden Center, Irbid Hearing and Speech Center.

\section{The Study Sample}

The researcher selected a number of centers in the Irbid Governorate. The administrations of these centers were assigned to distribute the study tool on an available sample from autistic children families, so that only one who can complete, After filling, 241 questionnaires were received, After checking the questionnaires, 44 were invalid queries and were excluded from analysis (44) were not valid for analysis because they were incomplete and were not filled in the correct way. Thus, the number of analyzed questionnaires which were statistically analyzed (197) that represent all members of the study sample.

\section{Study Tools}

The data was collected based on a questionnaire tool and was sent to families of autistic children in the care and rehabilitation centers. The questionnaire was prepared for the purpose of the study; it was presented to faculty members in Malaysia, Jordan, Egypt and Saudi Arabia. The questionnaire included 37 items distributed into (4) areas: The psychological constraints field for families of autistic children, social constraints for families of autistic children of, the economic constraints for families of autistic children, and the role of the family in the preparation and rehabilitation of autistic children.

\section{Study Results}

The results of the field study which aimed at identifying family constraints and their relation to the family role in preparation and rehabilitation of autistic children in Irbid governorate in Jordan where were the Questionnaire presented and according to its questions. 
INTERNATIONAL JOURNAL OF ACADEMIC RESEARCH IN BUSINESS AND SOCIAL SCIENCES

Vol. 8, No. 11, Nov, 2018, E-ISSN: 2222-6990 @ 2018 HRMARS

Question 1: What is the impact level of the psychological, social and economic constraints that limit the family role in preparation and rehabilitation of autistic children in the governorate of Irbid in Jordan?

- It was found that the psychological constraints that limit the family role in preparation and rehabilitation of the autistic child in Irbid governorate in Jordan were significant as the mathematical mean of the paragraphs as a whole was 3.5371 and the standard deviation is 0.92631

- It was found that the social constraints limit the family role in the preparation and rehabilitation of an autistic child in a medium degree as the arithmetic mean of the paragraphs as a whole is 2.9565 and a standard deviation of 86835

- The economic constraints that limit the family role in the preparation and rehabilitation of an autistic child were significant. The mathematical mean of the paragraphs as a whole was 3.5520 and with a standard deviation 1.13058

Question 2: Is there a difference in psychological, social and economic impact levels of constraints that limit the family role in the preparation and rehabilitation of an autistic child in Irbid governorate in Jordan according to the changes related to the parents?

- It was found that there is no difference in the level of psychological constraints that limit the family role in the preparation and rehabilitation of the autistic child in Irbid governorate in Jordan according to the variables: father's level of education and mother's level educational, and there is no difference depending on the social situation variable.

- There is a difference in the level of psychological constraints that limit the role of the family in the preparation and rehabilitation of the autistic child in the governorate of Irbid in Jordan depending on the income variable of the family as a whole, where the income of more than 1001 Jordanian dinars and those who income less than 500 Jordanian dinars and in favor for those who income less than $500 \mathrm{JD}$, and those who have income of more than $1001 \mathrm{JD}$ and those who have income of $501-1000 J D$ and in favor for those who have income from 5011000JD.

- There is a difference in the mental constraints levels that limit the family role in the preparation and rehabilitation of the autistic child in Irbid governorate in Jordan depending on the family residence variable and for the benefit of those living in the village. There is a difference in the level of psychological constraints that limit the family role in the preparation and rehabilitation of autistic child in Irbid in Jordan depending on the type of the family housing variable and it was in favor for those who live on rent houses.

- It was found that there is no difference in the social constraints that limit the family role of the autistic child rehabilitation according to the changes in the father's educational level, family income, place of residence, type of family housing.

- It was found that there is no difference in the social constraints that limit the role of the family in the rehabilitation of the autistic child according to the changes in the father's educational level, family income, place of residence, type of family housing.

- There is a difference in the social constraints level that limit the family role in the rehabilitation of autistic child according to the changes of mother's educational level, where the differences between mothers whose level of education is a diploma and those whose level 
of education is less than secondary education and for those whose level of education is less than secondary education, whose level of education is postgraduate and for those who have a diploma level.

- There are differences in the social constraints levels that limit the family role in the rehabilitation of the autistic child according to the social situation variable where the difference between the spouses together and husband's death and in favor of the husband's death.

- It was found that there is no difference in the economic constraints level that limit the family role in the rehabilitation of autistic child according to the residence variable.

- There is a difference in the level of economic constraints that limit the family role in the rehabilitation of autistic child according to the father's educational variable level, where it was between the lower level of the secondary education and between the diploma and bachelor degrees, and postgraduate studies and it was in favor for the lower level of public secondary school.

- It was found that there is a difference in the level of economic constraints that limit the rehabilitation of the autistic child, depending on the family income variable the where among those income less than 500 JD and between each of those who their income between 501 1000 and who are more than 1001 dinars and it was in favor for those who their income is less than $500 \mathrm{JD}$.

- There is a difference in the economic constraints level of that limit the rehabilitation of the autistic child according to the social situation variable where it was between the level of the spouses together and the divorced level and in favor of the level of the spouses together.

- There is a difference in the level of economic constraints that limit the rehabilitation of the child autistic according to the housing type variable and was between the level of rent and the level of the ownership and in favor of the level of rent.

The third question: Is there a difference in the level of the impact of the psychological, social and economic constraints that limit the role of the family in the preparation and rehabilitation of the autistic child in the governorate of Irbid in Jordan according to the changes related to autistic child?

- It was found that there is no difference in the level of mental constraints that limit the rehabilitation of autistic child according to the difference between the variable levels of (age of the child, the order of the child among his brothers, the degree of the case according to medical opinion)

- There are differences between the levels of the child gender variable as the location of the differences in the level of psychological constraints that limit the rehabilitation of the autistic child were between males and females and for the benefit of males.

- It was found that there are no differences between the levels of the variables (gender of the injured child, the age of the affected child, the order of the child among his siblings) at the level of social constraints that limit the qualification of the child autistic.

- There is a difference in the level of social constraints that limit the rehabilitation of the autistic child according to the degree of the situation variable according to the doctor opinion and in favor of the level of the severe situation and the levels weak and medium situations and in favor of the severe level. 
INTERNATIONAL JOURNAL OF ACADEMIC RESEARCH IN BUSINESS AND SOCIAL SCIENCES Vol. 8, No. 11, Nov, 2018, E-ISSN: 2222-6990 @ 2018 HRMARS

- It was found that there is no difference in the level of economic constraints that limit the child's eligibility for autism according to the variables (gender of the child, age of the child, degree of the case)

- There is a difference in the child order levels to affect the level of economic constraints that limit the rehabilitation of the autistic child as the site of differences was between the third child and between the first and second children and more than one person and it was for the first and second and more than one person.

Question 4: What is the family role level in preparation and rehabilitation of the autistic child in the governorate of Irbid in Jordan?

The family role level in preparation and rehabilitation of the autistic child was found to be very high, with an arithmetic mean of 3.8828 and a standard deviation of 0.79472

Question 5: What is the effect of the variables related to parents about the family role in preparation and rehabilitation of autistic child in the governorate of Irbid in Jordan?

In order to determine the effect of the variables related to parents about the family role in preparing and rehabilitation of autistic child, a hexadecimal analysis test was used as in the table below:

\begin{tabular}{|c|c|c|c|c|c|}
\hline Source & $\begin{array}{l}\text { Type III Sum } \\
\text { of squares }\end{array}$ & $\mathrm{DF}$ & Mean square & $\mathrm{F}$ & Sig. \\
\hline Corrected Model & 49.076(a) & 13 & 3.775 & 9.247 & 0.000 \\
\hline Intercept & 209.688 & 1 & 209.688 & 513.610 & 0.000 \\
\hline $\begin{array}{l}\text { Father's } \\
\text { Educational } \\
\text { level }\end{array}$ & 12.892 & 3 & 4.297 & 10.526 & 0.000 \\
\hline $\begin{array}{l}\text { Mother's } \\
\text { educational } \\
\text { level }\end{array}$ & 10.990 & 3 & 3.663 & 8.973 & 0.000 \\
\hline Family income & 5.760 & 2 & 2.880 & 7.055 & 0.111 \\
\hline Social status & 6.986 & 2 & 3.493 & 8.555 & 0.000 \\
\hline $\begin{array}{l}\text { Family } \\
\text { Residence }\end{array}$ & 2.556 & 2 & 1.278 & 3.131 & 0.436 \\
\hline $\begin{array}{l}\text { Type of family } \\
\text { housing }\end{array}$ & 8.978 & 1 & 8.978 & 21.990 & 0.000 \\
\hline Error & 74.712 & 183 & 0.408 & & \\
\hline Total & 3093.826 & 197 & & & \\
\hline Corrected total & 123.788 & 196 & & & \\
\hline
\end{tabular}

a R Squared $=.396$ (Adjusted R Squared $=.354$ )

- The table shows that there is no effect of the (family income, family residence) variables in the family role in the preparation of the autistic child, where the value of $F$ is 7.055 and 3.131 respectively, all of which are not statistically significant at the $\alpha \geq .05$

- There is effect of the variables related to parents (father's level of education, mother's level of education, social status, type of family housing) in the family role in preparation of the 
INTERNATIONAL JOURNAL OF ACADEMIC RESEARCH IN BUSINESS AND SOCIAL SCIENCES Vol. 8, No. 11, Nov, 2018, E-ISSN: 2222-6990 @ 2018 HRMARS

autistic child, with a value of $10.526,8.973,8.555$ and 21.990 respectively which are statistically significant at the $\alpha \geq 0.05$

To determine the location of differences between the levels of independent variables related to parents, the TOKI test was used as in the table:

\begin{tabular}{|l|l|l|}
\hline A: father's level of education & $\begin{array}{l}\text { B: mother's level of } \\
\text { education }\end{array}$ & $\begin{array}{l}\text { arithmetic mean Deference } \\
\text { between A and B }\end{array}$ \\
\hline Diploma & Less than secondary & $-.6018\left(^{*}\right)$ \\
\hline & Bachelor degree & $-.6625\left(^{*}\right)$ \\
\hline Mother's level of education A & Post graduate studies & $-.9306\left(^{*}\right)$ \\
\hline Diploma & Father's level of education & $\begin{array}{l}\text { arithmetic mean Deference } \\
\text { between A and B }\end{array}$ \\
\hline & Secondary level & $-.2998\left(^{*}\right)$ \\
\hline Bachelor degree & Bachelor degree & $-.7293\left(^{*}\right)$ \\
\hline Social status A & Post graduate studies & $-.8262\left(^{*}\right)$ \\
\hline Divorced & Secondary class & $.4295\left(^{*}\right)$ \\
\hline & Social status B & $\begin{array}{l}\text { arithmetic mean Deference } \\
\text { between A and B }\end{array}$ \\
\hline Type of housing A & spouses together & $-1.3878\left(^{*}\right)$ \\
\hline Rent & Husband's death & $-1.0278\left(^{*}\right)$ \\
\hline
\end{tabular}

- The table shows that the difference between the educational level of the father was among those with a diploma degree and among those who hold a lower degree than a secondary school certificate, a bachelor's degree and a postgraduate degree, and for those who hold less than a secondary school certificate and a bachelor's degree and postgraduate studies.

- The difference between mother's educational levels was among those who has a diploma and those with less than a secondary school certificate, a bachelor's degree and postgraduate studies and it was in favor for those with less than a secondary school certificate, a bachelor's degree and postgraduate studies, and those who hold a diploma and a secondary school degree and it was in favor of those who hold a diploma degree.

- It was found that the location of the differences between the housing type levels was between those who live in a rent house and those who live in an ownership house and in favor of rent houses.

Question 6: What is the impact of the variables related to autistic children in the family role in the preparation and rehabilitation of the autistic child in Irbid governorate in Jordan?

In order to determine the effect of the variables related to autistic children in the family role in the preparation and rehabilitation of autistic children, a quadratic analysis test was used as in the following table: 
INTERNATIONAL JOURNAL OF ACADEMIC RESEARCH IN BUSINESS AND SOCIAL SCIENCES Vol. 8, No. 11, Nov, 2018, E-ISSN: 2222-6990 @ 2018 HRMARS

\begin{tabular}{|l|l|l|l|l|l|}
\hline Source & $\begin{array}{l}\text { Type III Sum of } \\
\text { squares }\end{array}$ & DF & $\begin{array}{l}\text { Mean } \\
\text { square }\end{array}$ & F & Sig. \\
\hline Corrected Model & $14.918(a)$ & 9 & 1.658 & 2.847 & 0.004 \\
\hline Intercept & 644.714 & 1 & 644.714 & 1107.388 & 0.000 \\
\hline Gender & 0.005 & 1 & 0.005 & 0.009 & 0.926 \\
\hline Child's age & 1.727 & 2 & 0.863 & 1.483 & 0.230 \\
\hline Child order & 4.768 & 3 & 1.589 & 2.730 & 0.051 \\
\hline Autism degree & 8.171 & 3 & 2.724 & 2.678 & 0.004 \\
\hline Error & 108.870 & 187 & 0.582 & & \\
\hline Total & 3093.826 & 197 & & & \\
\hline Corrected Total & 123.788 & 196 & & & \\
\hline
\end{tabular}

a R Squared $=.121$ (Adjusted R Squared $=.078$ )

- The table shows that there is no effect of the variables related to autistic children (gender, child age, child order) and the role of the family in its preparation of the autistic child as $F$ value is $0.009,1,483$ and 2.730 respectively and It is not statistically significant at $\leq 0.05$

- The table shows the effect of the autism degree variable role in the family preparation of the autistic child, with $\mathrm{F}$ value of $4.678 \mathrm{~F}$, which is statistically significant at $\alpha \leq 0.05$

To determine the location of the differences between the levels of the variable of autism degree, a TOKI test was used as in the table below:

\begin{tabular}{|l|l|l|}
\hline Autism degree A & Autism degree B & $\begin{array}{l}\text { arithmetic mean Deference } \\
\text { between A and B }\end{array}$ \\
\hline Sever & Weak & $-.6590\left(^{*}\right)$ \\
\hline & Medium & $-.4130\left(^{*}\right)$ \\
\hline
\end{tabular}

The table shows that the differences are located between those who has a sever case and those whose condition is weak and moderate and in favor for those whose condition is weak and moderate, this means that the role of the family in the rehabilitation and preparation of the autistic child in weak and moderate cases is more than in severe cases.

\section{Study Recommendations}

1. To develop national programs to support families of children with autism financially.

2. Organizing home visits in remote areas for families of autistic children.

3. The need for a mutual relationship between parents and specialists to find out the most important outcomes of the treatment and training of autistic children.

4. The existence of a reciprocal relationship between all members of the family and the child is reflected in the responses of the child who has autism and thus alleviates the suffering of family members.

\section{ACKNOWLEDGEMENT}

Special thanks to Research Management, Innovation \& Commercialization Centre (RMIC) and University Sultan Zainal Abidin (UniSZA) for funding this research 
INTERNATIONAL JOURNAL OF ACADEMIC RESEARCH IN BUSINESS AND SOCIAL SCIENCES

Vol. 8, No. 11, Nov, 2018, E-ISSN: 2222-6990 @ 2018 HRMARS

\section{References}

Refaat, S. A. (2006). "Psychological and Social Needs of Parents of Mentally Retarded Children and Their Relationship to Family Consensus" unpublished Master Thesis, Zagazig University.

Najjar, A. S. (2006). Autism and Disorder Behavior. Jordan, Osama Al-Mashreq Cultural House.

Imam, M., Jawaldeh, F. (2010). Mental disability and life skills in light of the mind theory, Jordan, House of Culture.

Al-Zarir, Ai. (2009). Sources of Psychological Stress and Methods of Coping with Parents of autistic Children in Jordan and its Relation to Certain Variables. unpublished Master Thesis, Amman Arab University.

Khamis, N. (2011). Social Problems of Autistic Children Families in Saudi Arabia and Facing Them" Master Thesis, Yarmouk University.

Holroyd. J., Brown, N., Wikler, L., Simmons, J. Q. (1975). Stress in families of institutionalized and no institutionalized autistic children. Journal of Community Psychology, 3(1): 26-31.

Wolf., C., Noh, S., Fisman, Sandra. N., Speechley, M. (1989). Brief report: Psychological effects of parenting stress on parents of autistic children. Journal of Autism and Developmental Disorders, 19 (1): 157-166. 